in practice, achieved. It emphasizes that the problem can only be resolved by the pressure of public opinion and, in particular, when industry, commerce and public administration at all levels of responsibility, from higher management to supervision, share the serious concern voiced by a minority, to the extent of a readiness to extend day-time release and insist on including non-vocational as well as vocational studies.

The sharpest criticism made by the Committee is of some of the professional and examining bodies, the papers and syllabuses of which are framed to encourage the memorizing of facts rather than the discussion of underlying principles. This practice is largely responsible for the narrowness of certain technical studies, and the Committee believes that these bodies should be invited to re-assess the purpose and nature of their examinations. The Committee also comments on the unsatisfactory physical environment in which the work of technical institutions is often performed. It welcomes the recent relaxation of the utilitarian attitude of the Ministry of Education towards vocational education and hopes that local education authorities and governing bodies will now press forward with the improvement of physical conditions, including the equipment and maintenance of libraries, an increased supply of technical and non-technical books and periodicals, and the provision of adequate refectories, recreation and common rooms. The Committee believes that all education must aim at increasing human sympathy and understanding, sharpening æsthetic appreciation and giving a better command of language, and to this end it recommends that human relations in industry and commerce should be more widely studied and the æsthetic appreciation of design appropriately emphasized. It further recommends that, in technical and professional examinations at all levels, some regard should be had to the qualities derived from liberal studies, and directs attention to the value of short periods of residential education and of foreign travel. It suggests that the links between technical institutions and the responsible bodies in adult education could be strengthened with advantage to both and that the experiments being made in the university world on the reconciliation of vocational and liberal education could be profitably studied in relevance to other forms of higher education.

\section{INTAKE OF NUTRIENTS BY SUGAR-BEET}

\footnotetext{
A

STUDY of the interactions of nitrogen, phosphorus and potassium, supplied in leaf sprays or as fertilizer added to the soil, has been reported on by G. N. Thorne (J. Exp. Bot., 6, 16, 20 ; 1955). Among findings of special interest are the following.

When sugar-beet plants grown in pots were sprayed daily with nutrient solutions supplying nitrogen, phosphorus and potassium separately or in all combinations, with precautions to prevent spray falling on the soil in which the plants were grown, all three nutrients were absorbed through the leaves. In one experiment nitrogen and potassium, and in another only nitrogen, caused increases in plant dry weight and leaf-area. Swedes absorbed phosphorus from leaf sprays and from fertilizer applied to the
}

soil, but only the fertilizer caused an incroase in dry weight.

Absorption of any of the nutrients tested from a spray containing more than one nutrient was unaffected by the presence of others in the spray; but spraying with nitrogen-containing solutions increased the absorption of phosphorus and potassium from the soil, and potassium in sprays increased the uptake of phosphorus from the soil. Nitrogenous fertilizer applied to the soil increased the leaf-area of sugar-beet plants, and hence it also increased the amounts of nitrogen, phosphorus and potassium deposited on the leaves when they were sprayed with solutions of these nutrients, and the amounts absorbed from the spray into the plants. Phosphatic fertilizer had no effect on uptalie from leaf sprays. Potassic fertilizer did not affect leaf-area or the estimated volume of spray solution retained on the leaves; but it appeared to reduce uptake of potassium from the spray. Dry woight per plant was increased by all three nutrients in fertilizer, and sugar yield of the roots was increased by nitrogen and potassium in fertilizer, and by nitrogen in spray. Application of a nutrient in leaf spray reduced the responses in dry weight and sugar yield to the same nutrient applied in fertilizer to the soil.

\section{JUTE PRODUCTION AND RESEARCH}

$\mathrm{R}$ EADERS interested in the problems of jute production in India will find a comprehensive account of relevant matters in the annual report of the Indian Central Jute Committee (for 1953-54, pp. 1-300; Calcutta) and in the annual report of the Jute Agricultural Research Institute (1953-54, pp. 1-145; 1955 , Calcutta).

The primary object of this central authority is to deal with research on all aspects of jute from field to factory. The reports accordingly have sections devoted to the relevant agricultural, technological and economic aspects. At the Jute Agricultural Research Institute the programme includes jute breeding and eytogenetics, special problems of anatomy, the agronomy of jute and of crops yielding substitute fibres, and related physiological, microbiological and entomological problems. On the technological side, in addition to the normal testing, development and processing work, more fundamental researches on chemical and physical aspects have also been undertaken.

In investigations of the chemistry of the hemicelluloses of jute and other fibres it has been found that these are generally similar. Further evidence has been obtained supporting a hypothesis put forward earlier of a chemical combination between the carboxyl group of the hemicellulose and the hydroxyl group of the lignin in jute. On the physical side, the torsional rigidity of jute, ramie and sisal has been measured. It has been ascertained that heavier filaments have generally lower values for rigidity modulus and that porosity appears to be related inversely to rigidity. The elastic properties of jute filaments from plants at different stages of growth, and the effects of chemical and physical treatments on the hardness modulus of jute fibre, have been investigated. Some progress in X-ray investigations of jute fibre is also reported : here the principal aim was to ascertain the size of the micelles in fibres of different quality ratios. 